\title{
Comparative study of the invasiveness of Salmonella serotypes Typhimurium, Choleraesuis and Dublin for Caco-2 cells, HEp-2 cells and rabbit ileal epithelia
}

\author{
ALEX J. BOLTON, MICHAEL P. OSBORNE* and JOHN STEPHEN
}

Microbial Molecular Genetics and Cell Biology Group, School of Biological Sciences, University of Birmingham, Edgbaston, Birmingham B15 2TT and *Department of Physiology, Medical School, University of Birmingham, Edgbaston, Birmingham B15 2TT

\begin{abstract}
Patterns of invasiveness of Salmonella serotypes Typhimurium, Choleraesuis and Dublin in Caco-2 cells (without centrifugation) were compared with previously published studies of the rabbit ileal invasion assay (RIIA) and (where relevant) a HEp-2 cell invasion assay. Optimal conditions for the use of Caco-2 cell monolayers in bacterial invasion assays were defined. Centrifuge-assisted attachment of bacteria to cells was not used routinely as this increased the invasiveness of known hypo-invasive strains and detachment of Caco-2 cells. Inocula with too high bacterial numbers resulted in rapid acidification of media and detachment of the monolayers. The invasiveness of Typhimurium strains TML, WAKE, WII8, LT7, SL1027 and M206 in Caco-2 cells reflected that seen in the RIIA. The invasiveness of Choleraesuis strain A50 was similar to that in the RIIA except that bacteria grown at $37^{\circ} \mathrm{C}$ and used without storage at $4^{\circ} \mathrm{C}$ were slightly more invasive than those grown at $37^{\circ} \mathrm{C}$ and stored at $4^{\circ} \mathrm{C}$ before use. Dublin strain 3246 showed no apparent temperature-regulated invasiveness in Caco-2 cells, in contrast to the results observed in the RIIA. Dublin strain 3246 did not cleave tight junctions in the Caco-2 cell monolayer as it did in rabbit ileal epithelia both in vitro and in vivo. Three TnphoA insertion LPS mutants of Typhimurium TML were uniformly hypo-invasive in both Caco-2 cells and the RIIA; in contrast, they were differentially invasive in HEp-2 cells. Three smooth TnphoA insertion mutants of Typhimurium TML (invH, invG and pagC) were hypo-invasive in both the Caco-2 and HEp-2 cell invasion assays but not in the RIIA.
\end{abstract}

\section{Introduction}

Invasiveness of Salmonella serotypes for gut has been studied in vivo in several animal species including guinea-pigs [1], monkeys [2], rabbits [3], cattle and pigs $[4,5]$, chickens [6] and mice [7]. Also, successful attempts have been made to study invasiveness in gut explants of rabbit ileal mucosa [8,9], although less success was achieved with corresponding porcine and bovine explants because of technical difficulties in handling these tissues (unpublished data). However, the vast majority of invasion studies with salmonellae (and other invasive bacterial pathogens) have been carried out in vitro with cultured cell lines, often uncritically. The seduction of logistical convenience has tended to

Received 4 Oct. 1999; accepted 31 Oct. 1999.

Corresponding author: Dr J. Stephen. over-ride critical validation of cell systems as models for more complex differentiated tissues whose different cell types may have differing susceptibilities to invasion and different internalisation mechanisms [10].

In this laboratory, invasion data for salmonellae derived from studies with HEp-2 cells [11] were shown to differ in certain respects from those obtained in a rabbit ileal invasion assay (RIIA) in which explants of ileal epithelia are held in an asymmetric organ culture system [9]. The latter allows direct interaction of bacteria and differentiated enterocytes in situ [8]; a priori, the RIIA would be expected to provide a better in-vitro model for the study of bacterial invasion of the gut than de-differentiated cell lines.

In spite of the perceived advantages of the RIIA as an in-vitro system, the logistics of cost and labour intensity 
involved in RIIAs led to the use of a cell line being considered for some aspects of work in this laboratory, providing that such use could be justified experimentally. This paper describes the optimisation of an invasion assay for several strains of Salmonella with Caco-2 cell monolayers. Caco-2 cells and MDCK cells (of canine proximal tubule derivation) are among the best available to model gut epithelia; they form monolayers with tight junctions and by 10 days express small intestinal-like microvilli. Caco-2 cells were chosen as they are derived from human colonic carcinoma and, under appropriate monolayer culture conditions, differentiate to express microvilli and intercellular tight junctions resembling small intestinal epithelia [12]. Caco-2 cells have been used extensively in the study of bacteria-cell interactions. One such detailed study [13] involved one mouse- and pigvirulent strain of Salmonella serotype Choleraesuis and one mouse-virulent strain of Typhimurium. In the present study, several Typhimurium strains of human origin and one strain each of serotypes Choleraesuis and Dublin that had already been characterised biologically $[5,8,9,14]$ were used. The results from this study are compared with those from previous experiments with RIIAs and HEp-2 cells, and highlight the need for caution when extrapolating data from cell cultures to differentiated tissues and vice versa. Also, the findings in the present study differed in some important respects from those of Finlay and Falkow [13].

\section{Materials and methods}

\section{Bacterial strains}

Typhimurium strains. Strain TML is a human clinical isolate [15]. TNP1 and TNP5 are mutant derivatives of strain TML carrying a phoN lesion and nalidixic acid resistance $\left(\mathrm{NA}^{\mathrm{R}}\right)$; they differ only in the order in which phoN and $\mathrm{NA}^{\mathrm{R}}$ were introduced [9]. TNP1 and TNP5 were used to generate the following $\operatorname{Tn} p h o A$ insertion mutants with indicated invasive phenotypes. Smooth mutants 45 (invH), 81 (invH), 64 (pagC) and 83 (invG) were as invasive as their parents in the RIIA but hypoinvasive in HEp-2 cells [9]. Rough LPS mutants were differentially invasive: 41 and 85 were c. $50 \%$ less invasive than the parent strains in HEp-2 cells and 10fold less invasive than the parent strains in the RIIA [9]; 44 was as invasive as the parent strain in HEp-2 cells and 10-fold less invasive than the parent strain in the RIIA [9]. Strains W118 [3] and Wake [16] are human clinical isolates. Strains LT7, M206 and SL1027 are avirulent and hypo-invasive [8].

Choleraesuis. Serotype Choleraesuis var. kunzendorf strain A50 was isolated from a case of systemic salmonellosis in pigs in the UK [5].

Dublin. Serotype Dublin strain 3246 was isolated from a systemic case of salmonellosis in calves in the UK [5].

\section{Storage of bacterial strains, media and culture} conditions

These were as described previously [14].

\section{Caco-2 cells}

These were obtained from Dr T. Baldwin, University of Leicester and Dr J. H. Pearce, University of Birmingham. The cells were maintained in tissue culture medium (TCM, see below) with non-essential amino acids and antibiotics (TCMAa; see below).

\section{Buffers and media for cell assays}

Phosphate-buffered saline (PBS) was made up as follows: $\mathrm{NaCl}, 8.0 \mathrm{~g} ; \mathrm{KCl}, 0.2 \mathrm{~g} ; \mathrm{Na}_{2} \mathrm{HPO}_{4}, 1.43 \mathrm{~g}$ and $\mathrm{KH}_{2} \mathrm{PO}_{4}, 0.2 \mathrm{~g}$ dissolved and made up to $1 \mathrm{~L}$ with distilled water; $\mathrm{pH}$ adjusted to 7.3 with $\mathrm{HCl}$. TCM comprised the following: Minimal Essential Medium (LIFE, Paisley) containing Earle's salts but without glutamine. Glutamine was added to a final concentration of $2.0 \mathrm{mM}$ and Fetal Calf Serum (Northumbria Biologicals, Cramlington) to a final concentration of $10 \% \mathrm{v} / \mathrm{v}$. Tissue culture medium with non-essential amino acids and antibiotics (TCMAa): benzylpenicillin (LIFE) 100 units $/ \mathrm{ml}$ and streptomycin (LIFE) $100 \mu \mathrm{g} / \mathrm{ml}$ were added to TCM and non-essential amino acids (Sigma) were added to a final concentration of $1 \% \mathrm{w} / \mathrm{v}$. Trypsin/EDTA solution was obtained from LIFE.

\section{Plastic ware}

Falcon tissue culture flasks $\left(75 \mathrm{~cm}^{2}\right)$, flat-bottomed $24-$ well Falcon tissue culture plates and Falcon inserts (permeable polycarbonate, $9 \mathrm{~mm}$ diameter, $0.45 \mu \mathrm{m}$ pore size) were all obtained from Becton Dickson Labware (Microbiology Systems, Oxford). Sterilin universal containers $(30 \mathrm{ml})$ were supplied by Appleton Woods, Birmingham.

\section{Miscellaneous items for cell culture}

The study used dimethylsulphoxide (DMSO; Sigma), DPX mountant (Merck), gentamicin (Birmingham University Pharmacy) stock $40 \mathrm{mg} / \mathrm{ml}$ diluted to $100 \mu \mathrm{g} / \mathrm{ml}$ (final). Triton X-100 (Sigma) was sterilised by filtration and diluted 1 in 100 in PBS.

\section{Storage, recovery and passage of Caco-2 cells}

Cells were trypsinised from a flask containing a confluent monolayer (see below), concentrated by gentle centrifugation for $15 \mathrm{~min}$ at $4^{\circ} \mathrm{C}$, resuspended in TCMAa/DMSO $10 \%(1 \mathrm{ml})$ and dispensed into cryovials which were frozen at $-20^{\circ} \mathrm{C}$ for $6 \mathrm{~h}$ then at $-70^{\circ} \mathrm{C}$ for $24 \mathrm{~h}$ before freezing in liquid nitrogen. On recovery from liquid nitrogen storage, cells were quickly defrosted in a water bath at $37^{\circ} \mathrm{C}$ and added 
to TCMAa $(15 \mathrm{ml})$ and then transferred to a tissue culture flask. After overnight incubation to allow attachment of cells, the medium was changed to remove the toxic DMSO. When cell confluence was reached, medium was removed and the cells were washed twice in PBS $(10 \mathrm{ml})$. Trypsin/EDTA $(1.5 \mathrm{ml})$ was added to cover the monolayer and the excess was removed. The cells were incubated at $37^{\circ} \mathrm{C}$ for $5 \mathrm{~min}$. Following incubation the flask was tapped to dislodge the cells, which were then resuspended in TCMAa $(5 \mathrm{ml})$. Approximately $10^{6}$ cells $(1.5 \mathrm{ml}$ of suspension, after thorough pipetting to achieve even distribution of cells) were subsequently added to flasks containing TCMAa $(15 \mathrm{ml})$. The flasks were gassed with air $95 \% / \mathrm{CO}_{2} 5 \%$ in air for $30 \mathrm{~s}$ then incubated at $37^{\circ} \mathrm{C}$. Confluent monolayers were usually obtained at 3 days after passage. The cells were passaged no more than 20 times; after this, fresh cells were taken from stocks held in liquid nitrogen. Cells were routinely screened for mycoplasma contamination [17].

\section{Preparation of monolayers for Caco-2 invasion assay}

Caco-2 cells were trypsinised from a flask containing a confluent monolayer, resuspended thoroughly in TCMAa $(25 \mathrm{ml})$ and adjusted to $1 \times 10^{6}$ cells $/ \mathrm{ml}$ of TCMAa. TCMAa $(600 \mu \mathrm{l})$ was added to each well of 24-well tissue culture trays. Inserts were then placed in the wells and time was allowed for wetting by the medium. Cell suspension $(400 \mu \mathrm{l})$ was added to each insert. The plate was then gassed within a sealed box with $\mathrm{CO}_{2} 5 \%$ in air and incubated overnight at $37^{\circ} \mathrm{C}$ when confluent monolayers were formed. Ten days post-confluence, intestinal-like microvilli were maximally expressed (see Fig. 6c). Medium, above and below the inserts, was changed every 2 days. It should be noted that cells grew well on glass coverslips and both the quantitative invasion and electron microscopic data obtained were similar to those obtained with inserts. However, coverslips were not routinely used as this complicated the preparation of samples for electron microscopy.

\section{Preparation of bacterial inocula}

Strains were plated on to MacConkey agar or, in the case of Typhimurium mutants, appropriate selective media. Three colonies were picked and used to inoculate Hartley Digest Broth (HDB, Oxoid) $10 \mathrm{ml}$ and incubated at $37^{\circ} \mathrm{C}$ statically overnight. The culture was centrifuged $(5000 \mathrm{~g}, 10 \mathrm{~min}$, room temperature) and resuspended in HDB $(10 \mathrm{ml})$, of which $0.25 \mathrm{ml}$ was added to HDB $(20 \mathrm{ml})$ and incubated statically at $37^{\circ} \mathrm{C}$ for $3 \mathrm{~h}$. Bacteria were then centrifuged, resuspended in $5 \mathrm{ml}$ of TCM and adjusted appropriately, and used either immediately or after overnight storage on ice at $4^{\circ} \mathrm{C}$.

\section{Caco-2 cell invasion assay}

Before use, monolayers were washed with TCM (apically, $400 \mu \mathrm{l}$; basally, $600 \mu \mathrm{l}$ ). Bacterial suspensions were adjusted to $c .1 \times 10^{7} / \mathrm{ml}$ of TCM of which $400 \mu \mathrm{l}$ were added to each of four wells; trays were regassed in a sealed box and incubated at $37^{\circ} \mathrm{C}$ for $2 \mathrm{~h}$. Supernates were removed and the monolayers were washed once with PBS. Viable counts were performed on the medium underneath the inserts to ensure that there was no passage of bacteria through insert membranes; none was found under the conditions of these experiments. TCM ( $400 \mu \mathrm{l}$, containing gentamicin $100 \mu \mathrm{g} / \mathrm{ml}$ ) was added to each of the wells and incubation continued for a further $1 \mathrm{~h}$ at $37^{\circ} \mathrm{C}$. Monolayers were then washed twice with PBS. Cells were lysed by addition of Triton X-100 (400 $\mu \mathrm{l})$ for $10 \mathrm{~min}$ to release internalised bacteria; the bases of the inserts were then scraped with a surface-sterilised 'rubber policeman' [11] and the total lysate was pipetted vigorously to disperse aggregates of bacteria. Trays were held on ice at this stage. Viable counts (cfu/ml of lysate) were determined. In preliminary experiments it was established that the dose-response relationship between challenge inoculum and numbers of intracellular bacteria recovered was linear for inocula in the range $(1-3) \times 10^{7} \mathrm{cfu} / \mathrm{ml}$. Above this range, as in the HEp-2 cell system [11], the medium became acidic, cells began to detach and were observed floating in the medium, resulting in a decline in the fraction of bacteria recovered. Therefore, all experiments were performed with initial inocula $c$. $4 \times 10^{6} \mathrm{cfu} /$ monolayer. Invasion was assessed as the recovery of intracellular bacteria expressed as a percentage of the inoculum. The data were normalised to the positive control appropriate to the experiment, as this allowed inter-experimental comparisons to be made.

The centrifuge-assisted assays were performed as described previously [11].

\section{Scanning electron microscopy}

Inserts were immersed and fixed for $24 \mathrm{~h}$ in glutaraldehyde $2.5 \% \mathrm{v} / \mathrm{v}$ in phosphate buffer $(\mathrm{pH} 7.2)$, the osmolarity of which was adjusted to $350 \mathrm{mOsm}$ with sucrose, then processed and examined as described previously [14].

\section{Transmission electron microscopy}

Inserts were fixed for $1 \mathrm{~h}$ in glutaraldehyde $2.5 \% \mathrm{v} / \mathrm{v}$ and post-fixed in $\mathrm{OsO}_{4} 1 \% \mathrm{w} / \mathrm{v}$ for $1 \mathrm{~h}$; both glutaraldehyde and $\mathrm{OsO}_{4}$ solutions were made up in phosphate buffer ( $\mathrm{pH}$ 7.2) the osmolarities of which were adjusted to $350 \mathrm{mOsm}$ with sucrose. Inserts were then processed and examined as described previously [14]. 


\section{Results}

\section{Centrifuge-assisted attachment/invasion}

The effect of centrifugation - sometimes used to enhance the number of productive synchronous attachment/invasion events in invasion assays - was examined, as it has already been shown that, for some cases, bacterial internalisation by eukaryotic cells could be profoundly influenced by centrifuge-assisted attachment $[11,18]$. Avirulent Typhimurium SL1027 was chosen for the experiments described here, because it was more invasive than virulent Typhimurium strain TML in centrifuge-assisted invasion assays with HEp-2 cells [11], but in the RIIA it was less invasive than strain TML [8]. Centrifuge assistance increased the individual invasiveness of strains TML and SL1027 12fold and 28-fold respectively, and diminished the ratio of TML/SL1027 invasiveness from 4.2 without centrifugation to 1.7 with centrifugation. Centrifugation also resulted in loss of Caco-2 cells from the monolayers. Tn $p h o A$ LPS mutants 41, 44 and 85 were chosen because of their invasive phenotypes (see Materials and methods). Fig. 1 shows that the best reflection of RIIA data for the mutants [9] was obtained with non-centrifuge-assisted attachment in Caco-2 cell assays: strain SL1027 and mutants 41, 85 and 44 were all hypo-invasive. Therefore, non-centrifuge-assisted attachment was adopted as routine in all subsequent assays described below.

\section{Comparison of invasiveness of known virulent and avirulent strains of Typhimurium}

The pattern of invasiveness of the biologically welldefined Typhimurium virulent (TML, WAKE, W118) and avirulent (LT7, SL1027, M206) strains mirrored that of the RIIA [8], but not that of the centrifugeassisted HEp-2 assay [11] (Fig. 2).

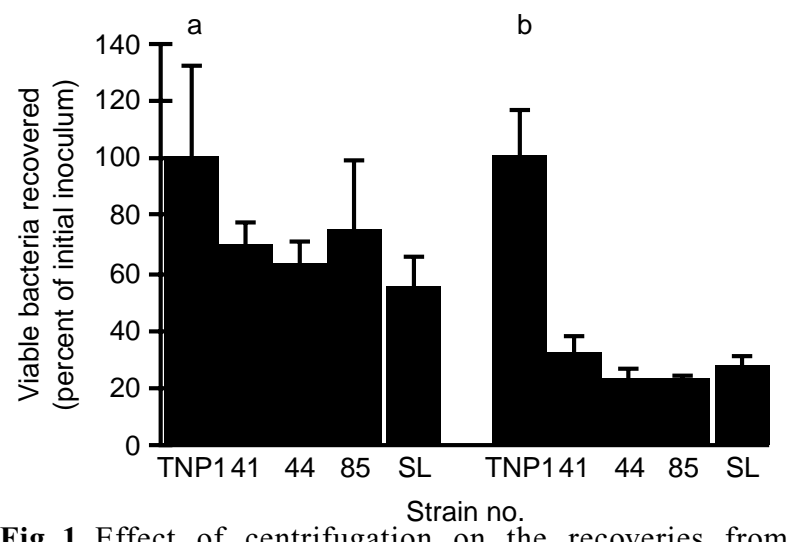

Fig. 1. Effect of centrifugation on the recoveries from Caco-2 cell invasion assays of Salmonella serotype Typhimurium strains TNP1 and SL1027 (SL) and Tn phoA LPS mutants $(41,44,85)$ of Typhimurium strain TNP1: (a) with centrifugation; (b) without centrifugation. Each column represents the mean and SEM of numbers of bacteria recovered from four separate wells. Data are normalised to Typhimurium TNP1. Note that, while absolute levels of invasiveness increased with centrifugation (see text), in every case differential invasiveness was maximal in the absence of centrifugation.

\section{Comparison of invasiveness of Typhimurium (TML) and its TNP1 and TNP5 derivatives}

No difference in the pattern of invasiveness of parent TML or TNP1 and TNP5 derivative strains was observed (Fig. 3); the result reflected that seen in RIIAs [9].

\section{Comparison of invasiveness of Typhimurium TNP1 and TNP5 and their smooth TnphoA mutants}

Mutants $45($ invH), $81($ invH), $64($ pagC) and $83($ invG) were hypo-invasive (Fig. 4) as seen in the HEp-2 cell assay [11]; in contrast they were as invasive as the

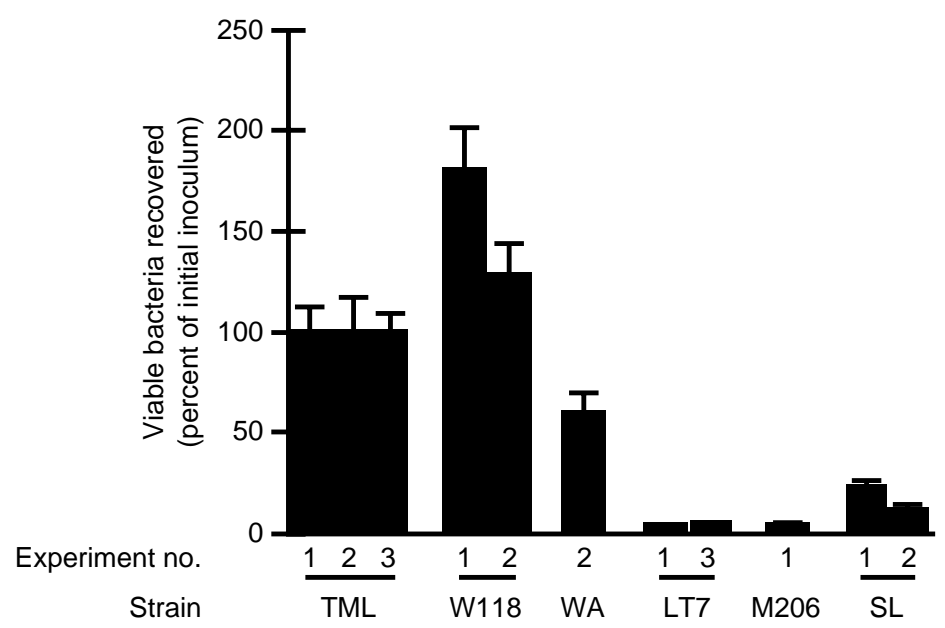

Fig. 2. Comparison of invasiveness of known virulent and avirulent strains of Salmonella serotype Typhimurium in Caco-2 cells. Biologically well-defined virulent strains TML, W118, WAKE (WA) and avirulent strains LT7, M206, SL1027 (SL) of Typhimurium were examined in three experiments. Each column represents the mean and SEM of numbers of bacteria recovered from four separate wells. Data are normalised to Typhimurium TML. 


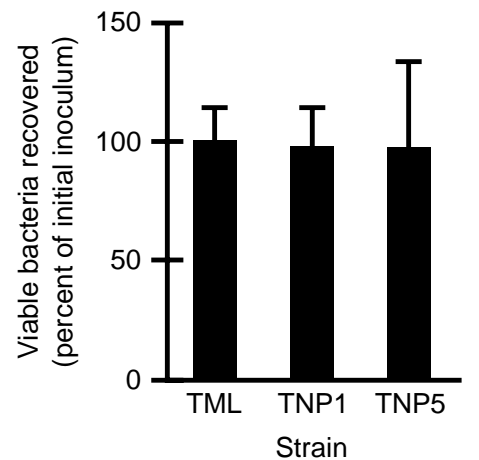

Fig. 3. Comparison of invasiveness of Salmonella serotype Typhimurium strain TML and its TNP1 and TNP5 derivatives in Caco-2 cells. Each column represents the mean and SEM of numbers of bacteria recovered from four separate wells. Data are normalised to Typhimurium TML.

parent strains in the RIIA [9]. This was the first and to date the only apparently anomalous result reported in the use of the RIIA (see Discussion).

Comparison of invasiveness of Choleraesuis A50 and Dublin 3246 after storage at $4^{\circ} \mathrm{C}$ or fresh preparations

Typhimurium strains TML and LT7 were used as positive and negative controls, respectively. There was little difference between the invasiveness of Dublin 3246 relative to Typhimurium strain TML at the two temperatures (Fig. 5a, b); this is in sharp contrast to the pattern in the RIIA in which the invasiveness of Dublin 3246 was greater when the bacteria were pre-stored at $4^{\circ} \mathrm{C}$ [14]. The invasiveness of Choleraesuis strain A50 increased slightly when used fresh and not pre-stored at $4^{\circ} \mathrm{C}$ (Fig. 5a, b); again this is in contrast to the RIIA pattern in which there was no temperature-dependent difference in invasiveness [14].

\section{Electron microscopy}

Fig. 6a shows an overview of control Caco-2 cell monolayers at 10 days. The cracks in Figs. 6a, $\mathrm{d}$ and $\mathrm{f}$ are caused by the preparation of monolayers for microscopy; there were no plaques in the monolayer from which cells had been removed. Fig. 6 shows the maturation of microvilli over the period of 5 (Fig. 6b) to 10 days (Fig. 6c). As might be expected [14] Choleraesuis strain A50 did not cause rapid cleavage of intercellular tight junctions; the monolayer remained intact (Fig. 6d, e). Choleraesuis always entered cells singly or in small numbers (Fig. 6e). Dublin strain 3246 did not cause rapid cleavage of the tight junctions of the Caco-2 cell monolayer, as evidenced by the preservation of the monolayer as a whole (Fig. 6f) and the retention of tight junction architecture even during extensive invasion of Caco-2 cells via microvilli (Fig. $6 \mathrm{~g}, \mathrm{~h}$ ). The tight junctions remained intact despite major loss of microvilli (Fig. 6h). Retention of junctional integrity is in sharp contrast to observations in RIIAs over a similar short time of bacterial cell interaction [14].

\section{Discussion}

The present study has shown that a carefully optimised Caco-2 cell system is relevant to the study of some but not all aspects of salmonella invasiveness for the gut. Several points are worthy of note.

First, it is essential to control bacterial cell densities in these experiments because, as shown in earlier work with HEp-2 cells [11], with higher bacterial numbers cell monolayers became detached as a result of bacterial metabolism and consequent acidification of the medium. Cell detachment was visualised by microscopy and reflected in a fall in recoveries of intracellular organisms as inoculum sizes were in-

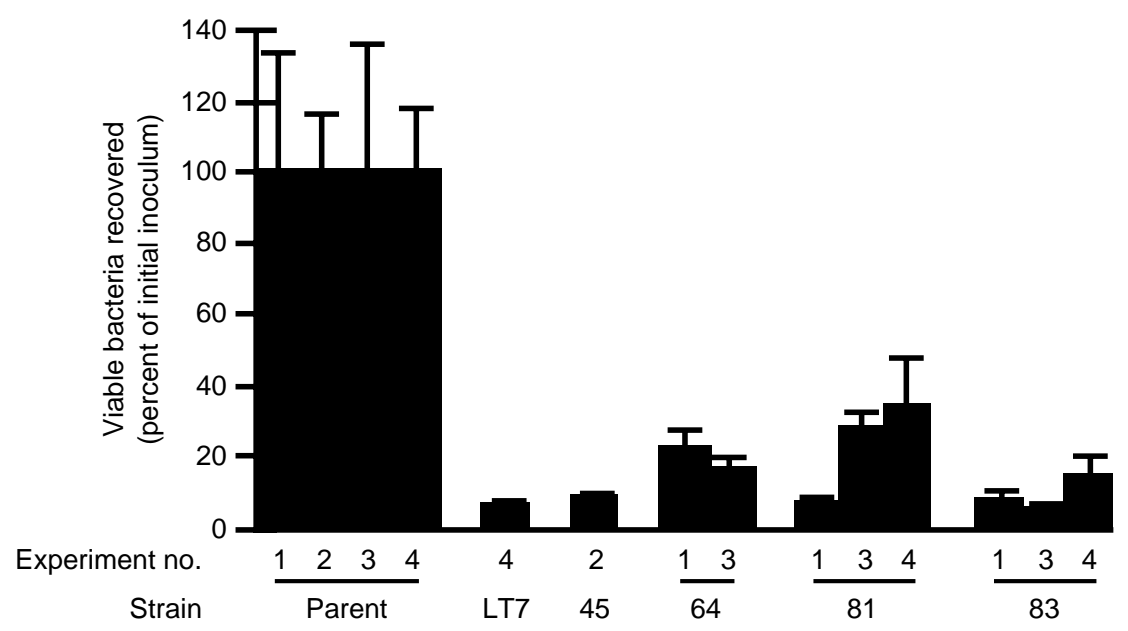

Fig. 4. Comparison of invasiveness of Salmonella serotype Typhimurium strains, TNP1, TNP5 and smooth TnphoA insertion mutants $i n v H(45,81)$, invG (83) and pagC (64) in Caco-2 cells. Each column represents the mean and SEM of numbers of bacteria recovered from four separate wells. Four experiments were performed and data are normalised to Typhimurium TNP1 (or TNP5) from which the mutants were derived. 


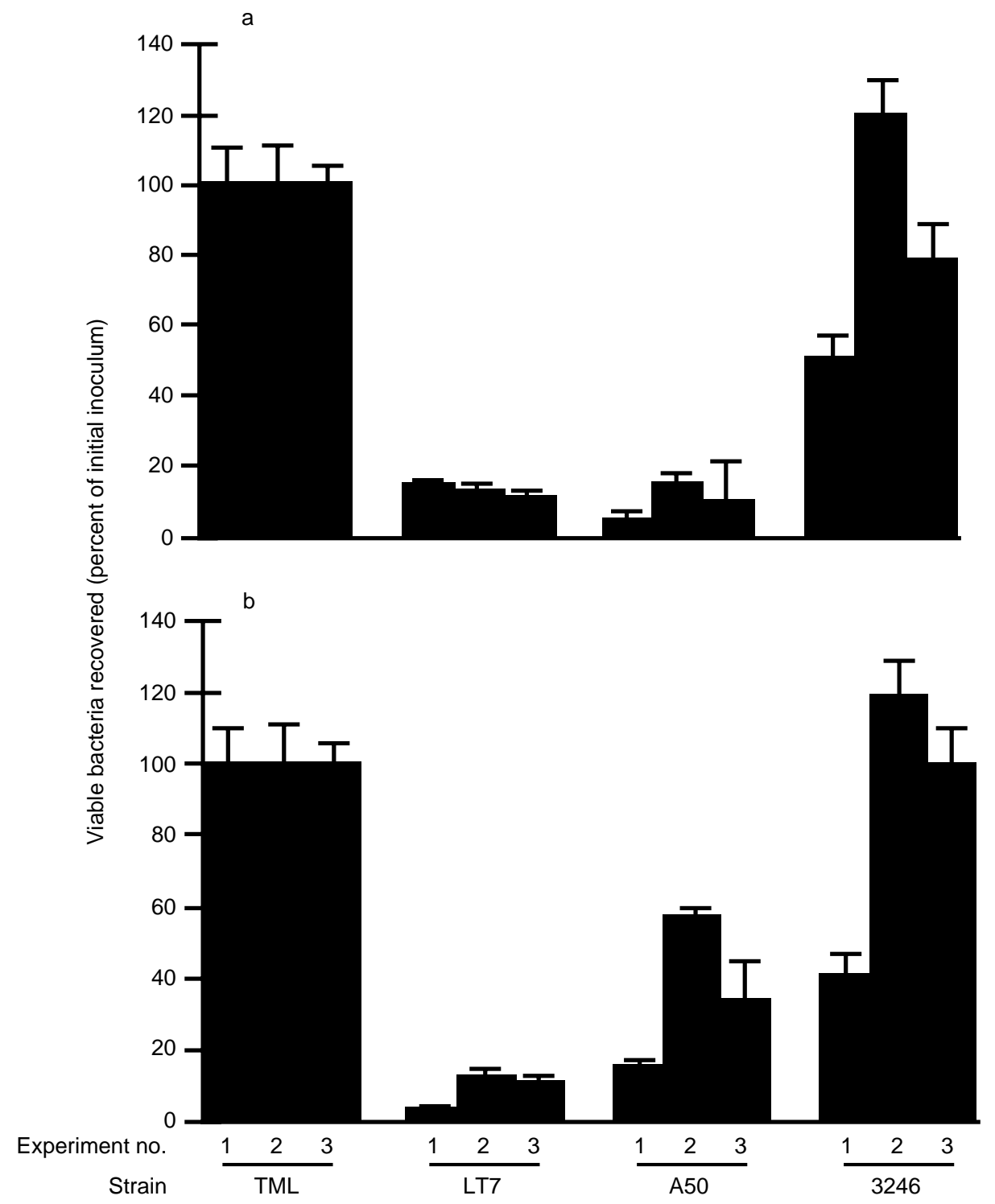

Fig. 5. Comparison of invasiveness of Salmonella serotype Choleraesuis strain A50 and Salmonella serotype Dublin strain 3246 in Caco-2 cells: (a) three experiments with bacteria grown at $37^{\circ} \mathrm{C}$ and stored at $4^{\circ} \mathrm{C}$ overnight; and (b) three experiments with bacteria grown at $37^{\circ} \mathrm{C}$ and used fresh. Typhimurium TML and LT7 were used as positive and negative controls, respectively. Each column represents the mean and SEM of numbers of bacteria recovered from four separate wells. The data are normalised to Typhimurium TML. The invasiveness of Choleraesuis A50 was slightly upregulated when used fresh, whereas invasiveness of Dublin 3246 was not affected.

creased above $1.2 \times 10^{7} \mathrm{cfu} /$ Caco- 2 cell monolayer; in this work, inocula were adjusted to $\leqslant 10^{7} \mathrm{cfu} / \mathrm{Caco}-2$ cell monolayer. In contrast, Finlay and Falkow [13] described the death of Caco-2 cells in their assays, which they ascribed to 'the large numbers of bacteria used to infect the Caco-2 cells and the absence of protective phagocytic cells'. A simple calculation involving numbers of bacteria, the volume of apical medium and the area of the monolayer shows that the initial 'bacterial cell density/monolayer area' was 13 times greater in the Finlay and Falkow [13] work compared with the present study. The surprisingly rapid bacterial penetration of the monolayers [13] may have been in part due to loss of cells from the Caco-2 cell monolayers as a result of using too dense inocula relative to the Caco- 2 cell monolayers. These are not hair-splitting points, as the principal reason why these cell-culture systems are used is to elucidate what happens in more complex epithelia like the gut itself.

Second, centrifugation also tended to cause detachment of cells. The fact that a higher degree of invasiveness was obtained when centrifugation was used, despite there being fewer residual adherent cells, must mean that centrifuge-assisted invasion assays give a falsely inflated estimate of the invasive potential of the organism under test. In other studies involving the internalisation of chlamydiae, centrifuge assistance resulted not only in different numbers of organisms being internalised but in different biological fates of the organisms [18]. Thus, it is not advisable to use centrifuge assistance in the expectation that a higher number of productive attachment/invasion events will take place in a shorter time. 

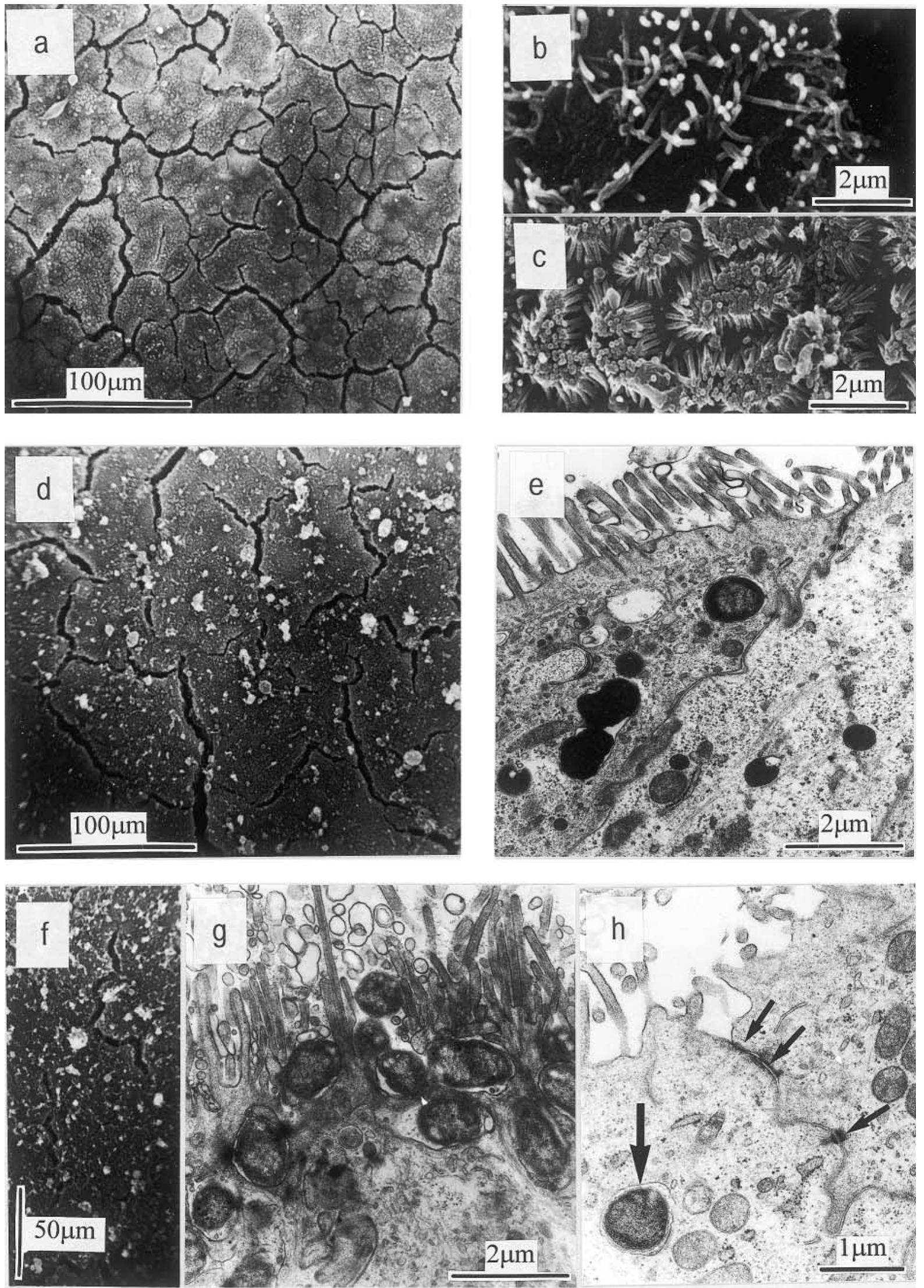

Fig. 6. Electron micrographs of Caco-2 cell monolayers. (a) Overview of 10-day-old uninfected control Caco-2 cell monolayer. (b) Microvillous structure of Caco-2 cells in monolayer at 5 days and (c) at 10 days, as used in all experiments. (d) Overview of monolayer infected with Choleraesuis A50. (e) Choleraesuis A50 organisms inside a Caco-2 cell showing minimal disruption of microvilli and intact junctional complexes. (f) Overview of monolayer infected with Dublin 3246. (g) Microcolony of Dublin invading Caco-2 cells via brush border. (h) Caco-2 cell, in same monolayer as in $(\mathrm{g})$ selected to show a Dublin 3246 organism inside a vacuole (large arrow), showing perturbation of microvilli but intact junctional complexes (small arrows). 
Third, the data presented here show that, in general, the patterns of relative invasiveness obtained in the RIIA are reflected in the optimised Caco- 2 cell invasion assay. For example, the original panel of biologically well defined Typhimurium virulent (TML, WAKE, W118) and avirulent (LT7, SL1027, M206) strains, Typhimurium TML derivatives TNP1 and TNP5, and the rough Tn phoA LPS mutants of Typhimurium strain TML all behaved in the same manner as in the RIIA $[8,9]$. Thus, for these strains, it would be valid to use the more convenient Caco- 2 cell invasion assay rather than the potentially more biologically relevant RIIA for comparative invasion studies. However, three examples were found where Caco-2 cell invasion data did not parallel the RIIA data. As it is assumed on a priori grounds that the RIIA system better reflects the situation in vivo, this calls for comment.

The first example concerns Choleraesuis, which showed an upregulated invasiveness when used fresh in Caco-2 cells, something that was not seen in the RIIA [14]. While no attempt was made to elucidate the basis of this difference, it could be postulated that mechanistic differences determine the efficiency with which Choleraesuis is internalised by differentiated rabbit ileal enterocytes and Caco-2 cells.

The second example concerns the behaviour of Salmonella serotype Dublin. Here, the differences between Caco-2 cell invasion data and those of the RIIA were dramatic. Dublin 3246 was of much higher invasiveness than Choleraesuis A50 when used fresh or pre-stored at $4^{\circ} \mathrm{C}$ and showed no decrease in invasiveness at the higher temperature as in RIIAs [14], but this can be explained. Despite invading across Caco-2 cell microvilli in huge numbers, the tight junctions remained intact when the experiments were performed at $37^{\circ} \mathrm{C}$; in contrast, epithelial tight junctions in RIIAs were disrupted by serotype Dublin and enterocytes were lost from the epithelium $[5,14]$. The significance of these results is considerable. By using short duration (2-3 h) Caco-2 cell tests it will be possible to dissect the invasive potential of Salmonella serotype Dublin from its epithelial tissue destructive property. Also, if the invasiveness of Dublin as seen in Caco-2 cells were to be interpreted in the context of its enteropathogenicity, this would achieve only a partial, and in one sense a misleading picture, as this organism is potently histotoxic in rabbits, pigs and calves $[5,14,19]$. There are at least two possible explanations for the discordance in RIIA/Caco-2 cell data obtained with Dublin. First, although Caco-2 cells are among the best in-vitro cell models available for studying the interaction of enteric pathogens and small intestinal epithelia, they are in fact of colonic origin. The tight junctions may well be sufficiently different from those of the small intestine as to be insusceptible to the effect of the toxin proposed as the microbial determinant responsible for the disruptive effects seen in rabbit, bovine and porcine small intestines $[5,14,19]$. Second, the histotoxin may not be expressed under the conditions of this assay. For this to be the case, the cessation of toxin production/release would have to be very rapid, as the preparation of bacterial inocula for the Caco-2 cell assay was identical to that for the RIIA right up to the final suspension in TCM immediately before their addition to Caco-2 cell monolayers.

The third example concerns the behaviour of the TML smooth mutant $45(i n v H)$. InvH is part of salmonella pathogenicity island 1 (SPI1), located at centisome 59, and involved in invasion of eukaryotic cells. InvH was hypo-invasive in the Caco- 2 cell assay (this work) and the HEp-2 cell assay [11]. However, as has already been pointed out, it was as invasive as its parent strain in the RIIA [9]. Superficially, this could be taken as yet another example of cultured cells exhibiting susceptibilities to bacterial invasion which are different from that of differentiated enterocytes in situ; and that may be correct. However, the problem is that another invH mutant of Salmonella serotype Typhimurium strain 4/74 (a virulent invasive bovine strain isolated from a case of salmonellosis in calves [20]) has been shown to be hypo-invasive in ligated loops of terminal ileum in calves $[5,20]$. Taken together with this work, it would appear that the patterns of invasiveness of invH mutants are better reflected in the cultured cell systems than in the RIIA. This is the only case we have found to date where the RIIA does not reflect the intact invivo situation; currently we have no rational explanation for the invH result. Unfortunately, there are no invivo data for $i n v G$ and $p a g C$, comparable to the $i n v H$ data, with which similar comparisons can be made. However, it does highlight the need for careful validation of systems which, for logistical reasons, are designed as less complicated substitutes for more complex in-vitro or in-vivo systems.

We thank the BBSRC for grant support for A. J. B., Paul Stanley (Physiology, Birmingham University) for technical assistance with electron microscopy and David Ruffles (Biological Sciences, Birmingham University) for photography.

\section{References}

1. Takeuchi A. Electron microscope studies of experimental salmonella infection. 1. Penetration into the intestinal epithelium by Salmonella typhimurium. Am J Pathol 1967; 50:109-136.

2. Rout WR, Formal SB, Dammin GJ, Giannella RA. Pathophysiology of salmonella diarrhoea in the rhesus monkey: intestinal transport, morphological and bacteriological studies. Gastroenterology 1974; 67: 59-70.

3. Wallis TS, Starkey WG, Stephen J, Haddon SJ, Osborne MP, Candy DCA. The nature and role of mucosal damage in relation to Salmonella typhimurium-induced fluid secretion in the rabbit ileum. J Med Microbiol 1986; 22: 39-49.

4. Frost AJ, Bland AP, Wallis TS. The early dynamic response of the calf ileal epithelium to Salmonella typhimurium. Vet Pathol 1997; 34: 369-386.

5. Bolton AJ, Osborne MP, Wallis TS, Stephen J. Interaction of Salmonella choleraesuis, Salmonella dublin and Salmonella typhimurium with porcine and bovine terminal ileum in vivo. Microbiology 1999; 145: 2431-2441.

6. Hassan JO, Curtiss R. Efficacy of a live avirulent Salmonella typhimurium vaccine in preventing colonization and invasion of 
laying hens by Salmonella typhimurium and Salmonella enteritidis. Avian Dis 1997; 41: 783-791.

7. Clark MA, Reed KA, Lodge J, Stephen J, Hirst BH, Jepson MA. Invasion of murine intestinal $\mathrm{M}$ cells by Salmonella typhimurium inv mutants severely deficient for invasion of cultured cells. Infect Immun 1996; 64: 4363-4368.

8. Amin II, Douce GR, Osborne MP, Stephen J. Quantitative studies of invasion of rabbit ileal mucosa by Salmonella typhimurium strains which differ in virulence in a model of gastroenteritis. Infect Immun 1994; 62: 569-578.

9. Lodge J, Douce GR, Amin II et al. Biological and genetic characterization of $\mathrm{Tn}$ phoA mutants of Salmonella typhimurium TML in the context of gastroenteritis. Infect Immun 1995; 63: $762-769$.

10. Stone BJ, Garcia CM, Badger JL, Hassett T, Smith RIF, Miller VL. Identification of novel loci affecting entry of Salmonella enteritidis into eukaryotic cells. $J$ Bacteriol 1992; 174: 3945-3952.

11. Douce GR, Amin II, Stephen J. Invasion of HEp-2 cells by strains of Salmonella typhimurium of different virulence in relation to gastroenteritis. J Med Microbiol 1991; 35: 349-357.

12. Pinto M, Robine Leon S, Appay MD et al. Enterocyte-like differentiation and polarization of the human colon carcinoma cell-line Caco-2 in culture. Biol Cell 1983; 47: 323-330.

13. Finlay BB, Falkow S. Salmonella interactions with polarized human intestinal Caco-2 epithelial cells. J Infect Dis 1990;
162: $1096-1106$.

14. Bolton AJ, Martin GD, Osborne MP, Wallis TS, Stephen J. Invasiveness of Salmonella serotypes Typhimurium, Choleraesuis and Dublin for rabbit terminal ileum in vitro. J Med Microbiol 1999; 48: 801-810.

15. Giannella RA, Formal SB, Dammin GJ, Collins H. Pathogenesis of salmonellosis: studies of fluid secretion, mucosal invasion, and morphologic reaction in the rabbit ileum. J Clin Invest 1973; 52: 441-453.

16. Wallis TS, Hawker RJH, Candy DCA et al. Quantification of the leukocyte influx into rabbit ileal loops induced by strains of Salmonella typhimurium of different virulence. $J$ Med Microbiol 1989; 30: 149-156.

17. Reynolds DJ, Pearce JH. Characterization of the cytochalasinD-resistant (pinocytic) mechanisms of endocytosis utilized by Chlamydiae. Infect Immun 1990; 58: 3208-3216.

18. Reynolds DJ, Pearce JH. Endocytic mechanisms utilized by Chlamydiae and their influence on induction of productive infection. Infect Immun 1991; 59: 3033-3039.

19. Lodge JM, Bolton AJ, Martin GD, Osborne MP, Ketley JM, Stephen J. A histotoxin produced by Salmonella. $J \mathrm{Med}$ Microbiol 1999; 48: 811-818.

20. Watson PR, Paulin SM, Bland AP, Jones PW, Wallis TS. Characterization of intestinal invasion by Salmonella typhimurium and Salmonella dublin and effect of a mutation in the invH gene. Infect Immun 1995; 63: 2743-2754. 